\title{
Lapurdum
}

Euskal ikerketen aldizkaria | Revue d'études basques |

Revista de estudios vascos | Basque studies review

$10 \mid 2005$

Numéro $X$

\section{Bernardo Atxagaren Lekuak: Obaba, edo « Arrazoi » modernoa eta oroimen postmodernoaren arteko borroka}

\section{Gorka Mercero Altzugarai}

\section{(2) OpenEdition}

12 Journals

\section{Édition électronique}

URL : http://journals.openedition.org/lapurdum/51

DOI : $10.4000 /$ lapurdum.51

ISSN : 1965-0655

Éditeur

IKER

\section{Édition imprimée}

Date de publication : 31 décembre 2005

Pagination : 127-136

ISBN : 2-86781-409-X

ISSN : $1273-3830$

Référence électronique

Gorka Mercero Altzugarai, «Bernardo Atxagaren Lekuak: Obaba, edo « Arrazoi » modernoa eta oroimen postmodernoaren arteko borroka », Lapurdum [Linean], 10 | 2005, Sarean emana----an 01 avril 2008, kontsultatu 21 septembre 2020. URL : http://journals.openedition.org/lapurdum/51 ; DOI : https://doi.org/10.4000/lapurdum.51 


\section{Bernardo Atxagaren Lekuak: Obaba, edo 'Arrazoi’ modernoa eta oroimen postmodernoaren arteko borroka ${ }^{1}$}

Zilegi bekit inpresio batekin hastea: postmodernitatearen diskurtsoa nekez ari zaigu sartzen euskal literatur kritikaren eremura. Diskurtso konplexua da oso, eta zehatzagoak izatekotan, postmodernitatearen diskurtsoei buruz hitz egin beharko genuke, pluralean, pentsamendu eta estetikaren korronte garaikide honen manualetan aspaldi samarrean topiko bihurtua den ideiaz baliatuz. Aniztasun eta desadostasun handiko debatea da postmodernitatearen ingurukoa, dagoeneko ekoiztu duen bibliografia zabalari oraindik ere etengabe ale berriak gehitzen ari zaiona, literatur teoria eta filosofia jorratzeaz batera, psikoanalisia edota soziologiari ere begiratzea eskatu ohi duena, diskurtso zaila, hitz batean esanda. Inpresioen bideari jarraituta, ideia postmodernoak euskal literatur kritikarenean berandutzearen kausa azken honen baliabide materialen urritasunean bila liteke, akaso. Bestalde, diskurtso postmodernoak leku orotan suertatzen (ari) dira zail 'digeritzen' eta hor ere egon liteke gurean berandutzearen beste arrazoietako bat. Edonola ere, konplexutasun eta zailtasun oro gorabehera, postmodernitateak aberastasun ideologiko-kritiko ukaezina dakarkigu, errealitatearen arlo guztietara zabal daitekeena, literatura barne. Modernitateak osatu duen tradiziotik erabat bereizteko bere ezina errekonozituta ere, postmodernitateak errealitatearen gaineko bestelako diskurtsoa dakarkigu, bestelako mundu ikuskera. Hori guztia jadanik ekartzen ari denari gurean lekua egiten laguntzea da honako lerro hauek eragin dituen asmoa.

Bernardo Atxagaren ekoizpena, oro har, eta Lekuak bere azken argitalpena partikularrean, postmodernitateak euskal literaturan egin duen bidetxoaren erakusgarri dira. ${ }^{2}$ Ezaguna da literatur kritikak eta historiak autoreak eta obrak sailkatu eta etiketatuz lan egiten dutela, besteak beste. Aski kritikatua ere izan da behar hori, baina zail da asmatzen sailkapen eta etiketarik gabeko lan-egitasmorik. Edonola ere, kritikarion esku badago lan-metodo horren inperfekzioa eta eraginkortasun gutxitua errekonozitzea: ez dago ezein obra literario zer den osoki adieraziko digun izenik edo etiketarik. Literatur

\footnotetext{
${ }^{1}$ Artikulu hau Eusko Jaurlaritzaren Hezkuntza, Unibertsitate eta Ikerketa Sailak emandako doktoregoaurreko beka bati esker idatzi ahal izan da.

${ }^{2}$ Bernardo Atxaga, Lekuak (Iruñea: Pamiela, 2005)
} 
kritikak ezintasunak eragindako umiltasunetik lan egin beharko luke beti. Horregatik, asmoa hemen ez da "Atxaga egile postmodernoa da” tankerako baieztapenen batera heldu eta balizko merituren bat aldarrikatzea kritikaren izenean edo izenarentzat. Postmodernitatearen etiketa hona ekartzearen helburua ez da determinatzailea, izen horrek Atxagaren lana zer den esan ahal baligu bezala. Asmoa estrategikoa baino ezin da izan, prozedurazkoa. Bestela esanda, kritikaren azken helburuak literaturaren zer hori atzematea izaten jarraitu behar badu ere, hau da, usu literaturaren esentzia edota literaturtasuna deitu ohi dena harrapatzea, zeregin hori burutzeko ezintasunak lan literarioa setiatzera, inguratzera bakarrik mugatzen gaitu eta horretarako estrategia egokiak garatzera, bere literaturtasuna hurbilagotik eta argiago ikusi ahal izango dugulako esperantzan.

Asmo estrategikoan, beraz, jarriko dira hemen Atxagaren Lekuak-eko pasarte batzuk eta hainbat ideia postmoderno elkarrizketan. Liburuaren lehen ataletan, Atxagak Obabako ipuin eta narrazioak eragin zituen gogoeta-lana azaltzen digu, besteak beste saiakera literarioaren forman. Gogoeta horrek errealitatearen zerizanaren gainean ohikoa ez den ikuspegia eskaintzen digu, Obabako unibertsora ez ezik, Atxagaren pentsaera politiko zein poetika literario orokorrera ere hurbiltzeko funtsezkoa dena. Artikulu honetan, Obaba, Euskal Herriko gatazka eta fikzio literarioa diren Lekuak-en hiru ardatz nagusietatik, ordea, lehenari bakarrik begiratuko diogu. Atxagak maiz plazaratu duen argudioa izan arren, errealitatearen gaineko bere ikuspegiak ez du, gure ustez, orain arteko iruzkin kritikoetan oihartzun handirik jaso, akaso ‘digeritzen’ zaila delako, arestian ideia postmodernoei buruz esan bezala. Edonola ere, bere oihartzuna indartzeko asmoz, ikuspegi hori hainbat ideia postmodernoren argitara azaltzeak azken hauen gainean luze samar jardutea eskatzen du. Behar honek eraman gaitu artikulu honen luzera osoa Lekuak-eko lehen atalari bakarrik eskaintzera, laster, akaso, etor litezkeen beste artikulutarako utziz politika eta poetika atxagatarretan errealitaterik ez dagoelako ideiak duen eraginaren iruzkina. 


\section{Obaba: ‘Arrazoia' ere 'mitoa' da; ‘Arrazoia' 'mitoa' ere bada}

Bernardo Atxagak sarritan aipatu izan du Obaba bere oroimenetik sortu zela, bere haurtzaro eta nerabezaroko bizipenen eszenatokitik, Asteasu, Albiztur eta Zizurkilek osatzen zuten mundutik alegia: 'Hainbat urteren buruan, leku hura oroimenean jiraka hasi zitzaidanean, beste izen bat eman nion nik: Obaba. ${ }^{3}$ Oroimen-lanaren fruitu da Obaba, beraz. Oroimen-lan hori, ordea, ez da mugatzen egunero esperimentatzen dugun gogorapen bilketa soilera. Hasteko, Atxagak berak dioen bezala, bere haurtzaroan edo nerabezaroan bizi izandakoa eta Obabako fikzioan agertutakoaren arteko harremana 'izugarri konplexua da, eta ekuazio batean errenditu ezina. ${ }^{4}$ Hori baino garrantzitsuago, Atxagarenean errealitatea metafisikoa beharrean diferentziala delako ebidentzia bihurtzen da oroimena, oroimen postmodernoaren adibidea, beraz, zeinak, ikusiko dugun bezala, modernitateak aldarrikatzen duen ezagutza esentzial edo absolutuaren abusuan erortzetik libratu beharko gintuzkeen.

Atxagaren oroimen-lana, hain zuzen ere, modernotzat jo daitekeen abusu batek eraginda abiatzen da eta abusu horren aurkako errebindikazio bezala garatzen. Herritik hirira ikastera heldu orduko, Atxaga gaztea Asteasuk-eta osatzen zuten lekua mespretxuz begiratua zela konturatu zen, atzerapena, basatasuna, ezjakintasuna eta hiri modernoak gaindituak bide zituen oker guztiak egozten zitzaizkiola. ${ }^{5}$ Hiriko kulturak aginduta, Atxagaren haurtzaroko mundua gainditu beharra zegoen, baztertu, ahazteko beharra. Mundu horrek ez zuen tokirik ezta modernitatea idazten ari zen aurrerabidearen 'Historian' ere. Oroimenak, ordea, kontrakoa erakusten zion Atxagari, han bazegoela zer gordea, zer zaindua, baita zer miretsia ere. Zer hori bazterketa eta ahanzturatik berreskuratzeko borroka bihurtu zen orduan, egileak berak dioskunez, idazteari ekiteko izan zuen akuilu ideologiko, intelektual eta etikoa. ${ }^{6}$

Borroka horrek bere garapen literarioaren azpitik hartu zuen bidea azaltzen digu Atxagak Lekuak-en, haurtzaroko munduari duintasuna itzuliko zion izenaren bilaketarena, alegia.' 'Rurala' esateak berekin zekarren konnotazio txarretatik libratzeko desioa izan zen, hain zuzen ere, egilea abiarazi zuena lehen izen hau ordezkatzeko

\footnotetext{
${ }^{3}$ Bernardo Atxaga, Lekuak, 14-5. orr.

${ }^{4}$ Ibid., 27. or.

${ }^{5}$ Ibid., 17-18. orr.

${ }^{6}$ Ibid., 29. or.

${ }^{7}$ Ibid., 16-24. orr. passim.
} 
egokiago baten xerka. 'Mitoa' etorriko zen gero, mundu hark sineskeriei atxikirik zirauela, 'Arrazoi’ modernoaren eremu argitsuetatik at zegoela azpimarratuz. Ez zen hau, ordea, azken hitza izango. ${ }^{8}$ Hitz definitiboaren aurkikuntza iritsi zen Atxaga ohartu zenean bere haurtzaro eta nerabezaroko munduko hainbat elementuk, hala erromatarren garaiko aztarna kulturalek nola mundu horrek psikoanalisiaren aditzerik ez izateak, kasu, komunean zuten ezaugarriaz: antzinatasuna. 'Zifra sekretua aurkitzea bezalatsu izan zen niretzat', dio Atxagak. ${ }^{9}$ Hor erabaki zen bere bilaketa, hor izan zuen bere oroimen-lanak helmuga.

Aurkikuntzaren egokitasuna, doitasuna eta balio aldarrikatzailea zalantzan jarri gabe ere, bere eraginkortasunaz, ordea, duda egin liteke: zenbateraino jabetzen da Lekuak-en irakurlea aurkikuntza honek modernitatearen nagusitasunezko jarrera kolokan jartzen duela eta bere abusuzko epaiak agerian uzten? Irakurleak antzinatasunaren lilura, milaka urteko tradizioak gorde dituen munduaren xarma -Lekuak-en hain ederki agertuasumatzearekin batera, ahaztuko al zuen, besterik gabe, bere ikuspegi modernotik arbuiagarriak diren mundu horren beste hainbat alderdi, Atxagak zintzoki ezkutatzen ez dituen sineskeriak, kasu? Ez ote da 'mito' hitzaren indarra handiegia izango ‘antzinatasun’ hitzarenarekin garaitzeko irakurlearen gogoan? Galdera hauek eraginda eta Atxagaren aurkikuntza indartzeko asmoz, Atxagaren idazkietan bertan aurki daitekeen beste osagai bat ekarriko dugu orain harira, bere aurkikuntzaren benetako pisua erakutsi ahal diguna. Lekuak-en ere aipatua den arren, bertan ez zaigu, akaso, egilearen beste hainbat testutan duen indar edo argitasunez agertzen: errealitatea interpretazioa delako ideiaz ari gara.

Aspaldikoa da Atxagak ideia honen inguruan agerturiko kezka eta oso deigarria eta nabarmentzekoa Obabakoak argitaratu zen garaian bere artikulu, hitzaldi zein

\footnotetext{
${ }^{8}$ Hemen, deigarri samarra egiten da egiaztatzea mundu harentzako izen egokiaren bilaketa bukatu gabe zegoela egileak jadanik Obaban kokaturiko hainbat lan argitaratuak zituenean. Atxagak dio mitoa azpimarratzen zuen azalpenari denbora luzean iritzi ziola ona, eta horretara jotzen zuela bere ipuinei buruz galdetzen ziotenean (ik. Bernardo Atxaga, Lekuak, 23. or.). Adibide polita da egileak beren obraren zentzuaz guztiz jabe izan ohi ez direlako ideia ilustratzeko.

${ }^{9}$ Ibid., 24. or.
} 
elkarrizketetan erdiesten duen zentraltasuna. ${ }^{10}$ Hona hemen Lekuak-eko Obabari buruzko ataletan ideia hau indartsuen azaltzen deneko pasartea osorik transkribatuta:

Noizbait, ez dakit non, estereotiposferan bizi ginela esan nuen, eta egia dela uste dut. Lekurik leku dabilenak estereotipoak, ideia arruntak, mendiak adinako topikoak aurkitzen ditu. Hala, Obabakoak euskal mundu ruralaren trasunto gisa ikusi dute askok, literatura obrak hortxe aurrean dagoen zerbaiten deskribaketa balira bezala, armairu bat ere hortxe dagoen bezala bernizatuko duenaren zain. Baina Nietzschek zioen ez zegoela gertaerarik, interpretazioak baizik. Hau da, ez zegoela errealitaterik, errealitate baten edo mila errealitateren sorketa baizik. ${ }^{11}$

Errealitaterik ez, baizik eta interpretazioak bakarrik daudelako nozioak diskurtso postmodernoekin eta berauek eskaintzen diguten bestelako mundu-ikuskerarekin jartzen gaitu harremanean zuzen-zuzenean. Jarraitzen ari garen argumentuaren puntu honetara helduta, ezinbestekoa zaigu konplexuak suerta daitezkeen hainbat argudio postmodernori heltzea, hasteko, Jacques Derrida pentsalariaren hainbat ideiari, hain zuzen. ${ }^{12}$ Hemengo sintesi-beharrak ez digu aukerarik emango ideia horiei zor zaien arretaz eta xehetasunez aritzeko. Barka bedi, beraz, azalpena zertzelada bakan batzuk ematera murrizten bada.

Zer da errealitatea Derridarentzat? Galdera honi erantzuteko modu bat Derridaren De la grammatologie liburuan aurki dezakegu, bertan Ferdinand de Saussure-ren hizkuntz teoriatik ateratzen dituen ondorioetan, hain zuzen ere. ${ }^{13}$ Zeinu linguistikoaren egitura osatzen duten adierazlea -osagai materiala, fonemen segida- eta adierazia osagai edukizkoa, esanahia- eta bi elementuon arteko harremanaren arbitrariotasunaz haratago, Saussure-k postulatutako hizkuntz sistemen izaera diferentzialari heltzen dio Derridak. Hasteko, Saussure-k dioenez, ‘[p]sikologikoki, gure pentsamendua, hitzen

\footnotetext{
${ }^{10}$ Ideia hau, gutxienez, 1982koa da, Jakin aldizkariko 'Literatura fantastikoa' izeneko artikulu batean agertzen zaigularik jada: ik. Bernardo Atxaga, 'Literatura fantastikoa', Jakin 25 (1982ko Urria-Abend.), 68-85. orr. (73. or.). Obabakoak-en garairako ik., besteak beste, 'Bihotzaren inbentarioa', El Diario Vasco. Zabalik (1989-6-7), 5. or; 'Obabakoak-en gainean', Enseiucarrean 5 (1990eko negua), 11-31. orr. (18-9. orr.)

${ }^{11}$ Bernardo Atxaga, Lekuak, 27. or.

${ }^{12}$ Jacques Derrida (1930-2004) dekonstrukzioa deitu ohi den pentsamendu estrategiagatik egin da ezagun mundu mailan. Dekonstrukzioa post-estrukturalismoaren ildokotzat jo ohi da batez ere, baina orokor samarra da postmodernitatearen barrukotzat jotzeko konbentzioa ere.

${ }^{13}$ Jacques Derrida, De la grammatologie (Paris: Minuit, 1967). Hemen, ingelesezko itzulpena erabili da: Of Grammatology, itzul. Gayatri Chakravorty Spivak (Baltimore: Johns Hopkins, 1976)
} 
bidezko adieraztea alde batera utziz gero, masa formagabe eta bereizgabea baizik ez da., ${ }^{, 14}$ Zentzu honetan, dio Saussurek, '[e]z dago aldez aurretik finkaturiko ideiarik, eta ezer ez zen bereizgarria, hizkuntza azaldu baino lehen. ${ }^{, 15}$ Baieztapen honek berak erabateko erronka egiten dio errealitatea eta hizkuntzaren arteko harremana azaltzeko modu metafisiko tradizionalari. Ondoren, Saussure-k iradokitzen du hizkuntza gure pentsamenduaren masa formagabean ebakitako elkarren ondoko xafletan egituratuta irudika daitekeela. Irudi horretan, adierazi bakoitzari xafla horietako bana dagokio. ${ }^{16}$ Beraz, adierazi bakoitzari dagokion esanahi-xafla, hots, zeinuaren edukia edo Saussure-k 'balio linguistiko’ deitzen duen hori beste zeinuei esleituriko esanahi-xaflen araberakoa da. Esanahia, ondorioz, ez da esentziala edo hizkuntz aurretikoa, testuinguruaren araberakoa eta diferentziala baizik. Honelaxe dio Saussure-k:

Balioak kontzeptuei dagozkiela esaten denean, jakintzat ematen da kontzeptu hauek bereizgarriak direla; ez daude positiboki definituak beren edukiaren arabera, baizik eta negatiboki, sistemaren beste terminoekiko erlazioengatik. Haien ezaugarri nagusia, besteak ez direna izatean datza. ${ }^{17}$

Puntu honetara helduta, Saussure-k atzera egiten du, bere postulatuak berekin dakarren ondorio ontologiko eta epistemologiko funtsezkoei ezikusiarena eginez-edo. Derridak, ordea, ideia garatu eta bere azalpen-potentziala ustiatu egiten du. Aztarnaren nozioa -la trace- aurkez daiteke orain. Hizkuntz sistemaren zeinu oro gainontzeko zeinuak ez direna bada, eta hori baino ez, orduan zeinu bakoitzak gainontzeko guztien marka jaso behar du nolabait. Bestela esanda, zeinu bakoitza ez da gainontzekoen aztarna baino, edo halako aztarnen sorta. Jakina, gainontzeko elementuak ere, beren aldetik, ez dira aztarnak baino. 'Aztarna oro aztarna baten aztarna da. Ezein elementu ez da inon presente (alternatiboki elementua falta dela esatea ere ez litzateke egokia, ordea), aztarnak besterik ez dago. ${ }^{\text {,18 }}$ Gauzak horrela, adierazle ororen erreferentea ez da adierazi bat, beste adierazleren

\footnotetext{
${ }^{14}$ Ferdinand de Saussure, Hizkuntzalaritza orokorreko ikastaroa, itzul. Isabel Arrigain (Bilbo: Klasikoak, 1998 [1916]), 146. or.

${ }^{15}$ Ibid.

${ }^{16}$ Ik. ibid., Saussure-ren liburuak berak dakarren irudia.

${ }^{17}$ Ibid., 152. or.

${ }^{18}$ Geoffrey Bennington \& Jacques Derrida, Jacques Derrida (Chicago: University of Chicago Press, 1993), 75. or. Kasu honetan bezala, euskaraz argitaratuak ez dauden erreferentzien itzulpenak nireak dira artikulu osoan zehar.
} 
bat(zuk) baizik; azken hauena, beren aldetik, beste adierazleren bat(zuk); eta, hala, azkenik gabe. Ezinezkoa da erreferentea bere baitan duen adierazlerik aurkitzea. Denotatzearen edota adieraztearen ekintzan, beraz, atzeratze bat agertzen da, esanahia etengabe geroratzen duen mugimendu amaigabe bat adierazleen kateak eragina, ez baitago kateko elementuei beren esanahi ideala berreskuratuko liekeen adierazi transzendentalik aurkitzerik inoiz.

Derridak mugimendu bikoitz horretan inskribaturik dakusa lengoaia, diferentziak sortzearekin batera geroratze amaigabe bat dakarren mugimenduan, alegia. Hemengo azalpenaren doitasunik eza gorabehera, horixe da berak différance deitzen duena -hemen dyferentzia hitzaz euskaratzea proposatzen duguna. ${ }^{19}$ Are gehiago, dyferentzia delakoak ez dio lengoaiaren eremuari bakarrik eragiten; dyferentziak giza esperientziaren eremu osoari eragiten dio, bai hizkuntzazkoari, bai hizkuntzatik at dagoela aldarrika daitekeenari; bai pentsamenduari, bai oroimenari, are pertzepzio-ekintza orori ere. ${ }^{20}$ Beraz, Mendebaldeko pentsamenduak bere sorreratik nahi izan duen ez bezala, mundua ez dago osatua ideia, izate eta entitate aldaezinen sail batez, zeinak, munduaz bide dugun pertzepzio okerraz haratago, benetako errealitatea osatuko lukeen eta munduaren jatorria, oinarria eta azken egia seinalatuko. Ez dago halako errealitaterik. Ezer izatekotan, errealitatea ez da esentziala, transzendentala edota metafisikoa, diferentziala baizik -edo, hobe idatzita, dyferentziala. Derridak ondorioztatzen duen bezala, ez dago errealitate dyferentzial horri erreferentzia egitea 'esperientzia interpretatzaile baten bidez baino. Esperientzia honek ez du esanahirik ez sortzen, ezta onartzen ere, igortze edo erreferentzia-egite dyferentzialezko mugimendu baten bidez baizik (de renvoi différantiel). That's all ${ }^{21}$,22

Gatozen berriro Atxagak idatzirikoaren harira: ez dago errealitaterik, interpretazioak baizik. ${ }^{23}$ Orain, akaso, beste modu batez uler liteke esaldi hau. Atxaga ez

\footnotetext{
${ }^{19}$ Derridak asmaturiko différance delakoa, frantsesezko 'différence' jatorrizkotik ahoskeran ez, baizik eta grafian bakarrik ezberdintzen da, hau da, idatzian bakarrik antzeman daitekeen diferentzia da. Hemen, antzeko harreman bat gogoan hartuta, dyferentzia proposatu dugu.

${ }^{20}$ Dyferentziak giza esperientziaren eremu osoa barne hartzen duelako oso azalpen argi baterako ik. Marika Enwald, Displacements of Deconstruction. The Deconstruction of Metaphysics of Presence, Meaning, Subject and Method, doktorego tesia (Tampere: University of Tampere, 2004), 134. or. passim.

21 'That's all' ingelesez dago Derridak frantsesez idatziriko jatorrizko testuan ere.

${ }^{22}$ Jacques Derrida, Limited Inc., itzul. S. Weber (Evanston: Northwestern University Press, 1988), p.148.

${ }^{23}$ Ohar bedi aurreko aipuan Derridak dioena -errealitatea esperientzia interpretatzaileen bidez bakarrik atzeman daitekeela- eta Atxagak esandakoa -ez dago errealitaterik, interpretazioak baizik- zein antzekoak diren.
} 
da errealitatea ukatzen ari, ez da esaten ari inguratzen gaituen mundua ez dela existitzen. Ukatzen ari dena da -Derrida bezala- munduaren izaera esentziala, metafisikoa, munduak barne hartzen dituen gertaerak, fenomenoak, izateak, entitateak eta ideiak zer diren eta zertan dautzan argiro eta zalantzarik gabe, modu zeharo ongi perfilatuan azaltzea ahalbidetuko lukeena. 'Ez noa argirantz, iluntasunak bultzatzen nau', idatzi du Atxagak Lekuak-en. ${ }^{24}$ Izan ere, ez dago errealitatearen gainean erabateko argitasuna zabalduko den unerik. Errealitatearen izaera dyferentzialak ezinezkoa egiten du ezagutza absolutuaren egitasmoa, modernitatearena alegia. Hortik ez da, halere, ezagutza ororen ezinezkotasun edota hutsaltasuna ondorioztatzen. Ezagutza transzendentala ukatzeak ez dakar berekin axolagabekeria edo indiferentzia. Kontrara, diferentziak agerraraztea da pentsamendu postmodernoaren helburua, esentziek beharrean diferentziek osatzen dutelako errealitatea: ez dago indiferentea izaterik diferentzien aurrean. ${ }^{25}$ Edonola ere, ezagutza transzendentalaren posibilitatea desagertu egiten da bere objektua, bere helburua, hots, esanahi transzendentala ukatua den momentutik.

Laburbilduz, eta argumentuan zehar zabaltzen aritu garen ildoak biltzen diren puntura helduta, ezagutza transzendentala ezinezkoa bada, hau da, beste edozein ezagutzaren gainetik egiaren neurria emateko balioko lukeen ezagutza ez bada posible, orduan ezagutza oro interpretazioak dira. Hots, ez dago errealitaterik, interpretazioak baizik. Hiri modernoak ezin du aldarrikatu Atxagaren haurtzaroko munduaren gaineko ezagutzazko nagusitasun funtsezkorik, berak ere ezin baitu esan zer den errealitatea. Obabaren 'mitoa' eta hiriaren edo modernitatearen 'Arrazoia' ez daude muga garbi batez bereizita. Honek ez du esan nahi, inondik ere, 'mitoa' eta ‘Arrazoia' gauza bera direla, eta Atxagak ere ezberdindu egiten ditu. ${ }^{26}$ Halere, ezberdintasun hau ez da erabatekoa,

\footnotetext{
${ }^{24}$ Bernardo Atxaga, Lekuak, 18. or.

${ }^{25}$ Jacques Derrida, Jean-François Lyotard eta Gilles Deleuze pentsalari postmodernoen lana batera izendatzeko 'diferentziaren filosofia' esan ohi da.

${ }^{26}$ Obabakoak-eko hainbat ipuinetan nabarmena da 'Arrazoia' eta 'mitoa' bereizteko asmoa. Camilo Lizardi kasu paradigmatikoa da honi dagokionez. Alde batetik, 'Arrazoia' eta 'mitoa' hurrenez hurren ordezkatzen dituzten Camilo Lizardi erretorea eta Obabako biztanleen arteko urruntasuna azpimarratzen du Atxagak. Mari Jose Olaziregik seinalatu bezala, Camilo Lizardik bere gutunean agertu estiloak, zeinak Juan Bautista Agirre Asteasukoaren (1742-1823) idazkera imitatzen duen, urruntasun hori markatzeko funtzioa dauka, 'distantzia estilistikoaz bat desberdintasun sinbolikoa ere' adierazten duelarik. Ik. Mari Jose Olaziregi, Bernardo Atxagaren irakurlea (Donostia: Erein, 1998), 121-2. orr.; ik. baita ere Mari Jose Olaziregi, Waking the Hedgehog. The Literary Universe of Bernardo Atxaga (Reno: Center for Basque Studies. University of Nevada, 2005), 148-9. orr. Bestetik, ipuin berean narratzaile-transkribatzailearen deskribapena eta Camilo Lizardiren kontaketaren arteko distantzia ere zorrozki markatuta dago, hainbat kritikarik antzeman bezala: Mari Jose Olaziregik maila narratiboaren bikoizketa seinalatzen du, Jon
} 
biak ala biak baitira munduaren interpretazioak. Derridak argudiatzen duen bezala, 'Arrazoiak' eta 'mitoak' ez diete kontrako bi logika motari jarraitzen. ${ }^{27}$ Areago, 'Arrazoiak' ezin du aldarrikatu sineskeria edo 'mitoa' guztiz gainditu izana. Hitz batean esanda, 'Arrazoia’ ere ‘mitoa’ da; 'Arrazoia' 'mitoa’ ere bada.

Horixe da Atxagaren errebindikazioaren atzean ikus daitekeen euskarri filosofikoa, eta hortik eratortzen da bere aurkikuntzaren egokitasun, doitasun eta balio aldarrikatzailea. Asteasu, Albiztur eta Zizurkil haietako zein hiri modernoko kulturak edo mundu-ikuskerak ez dira interpretazioak baino: antzinakoa hura, medikuntzak errabiaren aurka aurkituriko tratamenduen edota psikoanalisiak garaturiko diskurtsoaren aditzerik ez zuena; berriagoa hau, ezagutza eta diskurtso horiek bereganatu dituena. Funtsean, beraz, denboraren akzidente batek erabakitzen du bien arteko diferentzia.

Metafisikaren hatsarreak adierazten du 'gizakien egiteko bakarra oinarri bat aurkitzea dela, egiari atxikirik hitz egiteko eta ona edo justuaren arabera jokatzeko aukera eskainiko duen oinarria, alegia' ${ }^{28}$ Berekin dakarren asmo ona gorabehera, hatsarre hau bera da, askotan, injustiziaren iturburu lehena, dyferentziala den errealitatea esentzializatuz, diferentziak ezabatuz, berdintasunak ukatuz, inposatuz, totalizatuz... Guztia ere, ‘errealitatea’ eta 'ezagutzaren’ izenean. Metafisikoa da modernitatearen egitasmoaren hatsarrea, 'Arrazoia' gidari gizateria ezagutzaren bidetik aurrera egiten ikusi nahi lukeena, ezagutza absolutua eta justizia unibertsalaren helmugara iritsi arte. Egitasmo horretan, oroimena ezagutzaren gordailua da, egindako okerrak gogoratuz iraganeko aurreiritzi eta sineskeriak gainditzea eta perfekzio-maila altuago batetik aurrerabideari berriro ekitea ahalbidetuko lukeena. Baina errealitate metafisikorik ezean, proiektu horrek ez dauka saihesterik aurreiritzi eta sineskeriatan behin eta berriro erortzea. Jean-François Lyotard-ek dioen bezala, oroimena hala ulertzen bada, alegia 'okerbiderarazten gaituzten gaitzen sorburu ezkutuak bilatze, aukeratze eta izendatzea

Kortazarrek narrazio hotz eta beroaz hitz egiten du, eta Joseba Gabilondok diskurtsoaren Hemen eta narrazioaren Hor aipatzen ditu. Ik., hurrenez hurren, Mari Jose Olaziregi, Bernardo Atxagaren irakurlea, 104-5. orr.; Jon Kortazar, Literatura vasca siglo XX (Donostia: Etor, 1990), 134. or.; Joseba Gabilondo, 'Obabazkoak. Alegoria topologiko baten irakurketa politikoa', in Joseba A. Lakarra (ed.), Memoriæ L. Mitxelena Magistri Sacrum, Pars Altera. ASJU gehigarriak, XIV (Donostia: Gipuzkoako Foru Aldundia, 1991), 1257-81 orr. (1266-7. orr.)

${ }^{27}$ ik. Jacques Derrida, Dissemination, itzul. Barbara Johnson (Chicago: University of Chicago Press, 1983), 61-162.orr. passim.

${ }^{28}$ Jean-François Lyotard, 'Rewriting Modernity’, in The Inhuman. Reflections on Time, itzul. Geoffrey Bennington \& Rachel Bowlby (Stanford, California: Stanford University Press, 1992) 24-35. orr. (28. or.) 
bezala, hots, gogoratze prozesu soil bezala, ekidinezina suertatzen da bidegabekeriak betikotzea, eta bidegabekeriak berriro ere burutzea berauei azkena eman beharrean. ${ }^{29}$

Oroimen postmodernoak ihes egiten dio metafisikari eta egitasmo modernoak errealitatea goitik behera ezagutzeko eta menperatzeko behar dituen oinarri transzendentalen bilaketari. Errealitatearen izaera dyferentzialari eutsiz, kategoria modernoek ezabatzen dituzten diferentziak agerrarazten ditu, joera metafisikoen baitako arrisku totalitarioei aurre egiteko helburuarekin. Atxagak Obaba sortuz garatu zuen oroimen-lanean ere hala gertatzen da. Obaba ez da Atxagak desagertzen ikusi zuen munduaren irudi gogoratua, egilearen oroimenetik paperera iraulia eta hala berreskuratua, ez hori bakarrik, behintzat, hori ere baden arren. Egileak berak dioen bezala, Obabako ipuin eta narrazioak ez dira hartu behar 'hortxe aurrean dagoen zerbaiten deskribaketa balira bezala, armairu bat ere hortxe dagoen bezala bernizatuko duenaren zain. ${ }^{30}$ Obabaren bidez garaturiko oroimen-lana, oroz gain, diferentzien agerraraztea da. Ez, ordea, Atxagaren haurtzaroko munduak hirian topatu zuenarekin zituen diferentzien agerpena, hori ere baden arren. Izan ere, Atxagak paperera irauli zuen oroimena ez da Asteasu, Albiztur eta Zizurkilek osatzen zuten munduarena bakarrik, hirian ezaguturiko kulturarena ere bada; bi mundu horien arteko tentsiotik sortzen da Obaba, bi munduen arteko diferentziek garrantzi handia hartzen dutelarik. Halere, beste bat da Obaban Atxagak agerrarazten duen diferentzia funtsezkoena: 'Arrazoiaren' baitako diferentzia, 'Arrazoiaren' barne diferentzia, bere buruarekiko duena, hain zuzen ere. Diferentzia horren agerpena da Atxagaren oroimen-lanaren giltzarria, 'Arrazoia' ere 'mitoa' dela, edo 'Arrazoia' 'mitoa' ere badela erakutsiz haurtzaroko mundua errebindikatzeko eta jasandako mespretxuzko abusua salatzeko aukera ematen diona.

Oroimen postmodernoaren lana, beraz, errealitatea menperatzen edota mundua ezagutzen dela aldarrikatu gabe diferentziak agerian uzten saiatzea da. Beharrezkoa da ez ezagutzea. Beharrezkoa da gogoratzea ezagutu gabe. Horixe baitugu aukera bakarra, arrakasta-bermea ez den arren, iraganeko bidegabekeriak ez errepikatzeko.

\footnotetext{
${ }^{29}$ Jean-François Lyotard, 'Rewriting Modernity’, 28. or.

${ }^{30}$ Bernardo Atxaga, Lekuak, 27. or.
} 


\section{Erreferentziak}

Atxaga, Bernardo, 'Literatura fantastikoa', Jakin 25 (1982ko Urria-Abend.), 68-85. orr. , 'Bihotzaren inbentarioa', El Diario Vasco. Zabalik (1989-6-7), 5. or. , ‘Obabakoak-en gainean', Enseiucarrean 5 (1990eko negua), 11-31. orr. , Lekuak (Iruñea: Pamiela, 2005)

Bennington, Geoffrey \& Jacques Derrida, Jacques Derrida (Chicago: University of Chicago Press, 1993)

Derrida, Jacques, Of Grammatology, itzul. Gayatri Chakravorty Spivak (Baltimore: Johns Hopkins, 1976) 1983), , Dissemination, itzul. Barbara Johnson (Chicago: University of Chicago Press, , Limited Inc., itzul. S. Weber (Evanston: Northwestern University Press, 1988)

de Saussure, Ferdinand, Hizkuntzalaritza orokorreko ikastaroa, itzul. Isabel Arrigain (Bilbo: Klasikoak, 1998 [1916])

Enwald, Marika, Displacements of Deconstruction. The Deconstruction of Metaphysics of Presence, Meaning, Subject and Method, doktorego-tesia (Tampere: University of Tampere, 2004)

Gabilondo, Joseba, 'Obabazkoak. Alegoria topologiko baten irakurketa politikoa', in Joseba A. Lakarra (ed.), Memorice L. Mitxelena Magistri Sacrum, Pars Altera. ASJU gehigarriak, XIV (Donostia: Gipuzkoako Foru Aldundia, 1991), 1257-81 orr.

Kortazar, Jon, Literatura vasca siglo XX (Donostia: Etor, 1990)

Lyotard, Jean-François, 'Rewriting Modernity', in The Inhuman. Reflections on Time, itzul. Geoffrey Bennington \& Rachel Bowlby (Stanford, California: Stanford University Press, 1992) 24-35. orr.

Olaziregi, Mari Jose, Bernardo Atxagaren irakurlea (Donostia: Erein, 1998) , Waking the Hedgehog. The Literary Universe of Bernardo Atxaga (Reno: Center for Basque Studies. University of Nevada, 2005) 